\title{
QUESTÕES ÉTICAS ENVOLVIDAS NA PRÁTICA PROFISSIONAL DE ENFERMEIROS DA COMISSÃO DE CONTROLE DE INFECÇAO HOSPITALAR'
}

\author{
Débora Cristina Ignácio Alves ${ }^{2}$ \\ Yolanda Dora Martinez Évora ${ }^{3}$
}

Alves DCI, Évora YDM. Questões éticas envolvidas na prática profissional de enfermeiros da comissão de controle de infecção hospitalar. Rev Latino-am Enfermagem 2002 maio-junho; 10(3):265-75.

Este trabalho foi realizado segundo a metodologia qualitativa, utilizando-se o método da análise de conteúdo de Bardin $^{(3)}$. Objetivou-se resgatar, junto aos enfermeiros de Comissão de Controle de Infecção Hospitalar (CCIH), suas percepções sobre as questões éticas, inerentes a sua prática profissional; apreender, junto aos enfermeiros assistenciais, a visão deles em relação à prática profissional do enfermeiro da $\mathrm{CClH}$, tendo em vista os aspectos éticos. Como possibilidades de uma prática profissional ética, eficaz e eficiente, haveria a necessidade de transformações de cunho governamental, reconhecimento profissional por meio da autonomia, respeito e exclusividade no Serviço de Controle de Infecção Hospitalar, além de melhorias nos vários aspectos da informação, da assistência prestada ao paciente e do sigilo profissional. O predomínio de atividades burocráticas e o trabalho em equipe como fator diferenciador das atividades realizadas pelo enfermeiro da Comissão, foram aspectos relevantes apreendidos pelos enfermeiros assistenciais.

DESCRITORES: ética, ética de enfermagem, infecção hospitalar/prevenção e controle

\section{ETHICAL ISSUES LINKED TO THE PROFESSIONAL PRACTICE OF NURSES THAT ARE MEMBERS OF A HOSPITAL INFECTION CONTROL COMMISSION}

This qualitative work was developed according to Bardin's ${ }^{(3)}$ method of content analysis. It aimed at finding out the perceptions of nurses that are members of a Hospital Infection Control Commission about ethical issues that are inherent to their professional practice as well as understanding the clinical nurses opinion regarding the professional practice of the nurses that are members of the Hospital Infection Control Commission, considering the ethical aspects. In order to achieve an ethical, efficient and effective professional practice, there is a need for governmental changes and professional recognition through autonomy, respect and exclusivity in the Service of Hospital Infection Control, as well as improvements regarding information, the care provided to the patient and professional secret. The predominance of bureaucratic activities and team work were mentioned by the clinical nurses as differentiating factors of the activities performed by nurses that are members of the Commission.

DESCRIPTORS: ethic, nursing ethics, hospital infection/prevention and control

\footnotetext{
${ }^{1}$ Versão condensada da Dissertação de Mestrado apresentada à Escola de Enfermagem de Ribeirão Preto, da Universidade de São Paulo; ${ }^{2}$ Enfermeira, Docente do Curso de Enfermagem da Universidade Estadual do Oeste do Paraná, Mestre do Programa de Mestrado Interinstitucional em Enfermagem Fundamental entre a Escola de Enfermagem de Ribeirão Preto/USP e UNIOESTE; ${ }^{3}$ Enfermeira, Professor Associado da Escola de Enfermagem de Ribeirão Preto, da Universidade de São Paulo, Centro Colaborador da OMS para o desenvolvimento da pesquisa em enfermagem, e-mail: ydmevora@eerp.usp.br
} 


\section{CUESTIONES ÉTICAS COMPROMETIDAS EN LA PRÁCTICA PROFESIONAL DE LOS ENFERMEROS DEL COMITÉ DE INFECCIONES INTRAHOSPITALARIAS}

Este trabajo fue realizado según la metodología cualitativa, usando el método de análisis de contenido de Bardin $^{(3)}$. Relata las percepciones en relación con los aspectos éticos de la práctica profesional del enfermero del comité de infecciones intrahospitalarias. (CII), sus percepciones y expectativas en relación con la práctica profesional del enfermero de este comité, Como posibilidades de una práctica profesional ética, eficaz y eficiente, habría la necesidad de transformaciones gubernamentales, reconocimiento profesional por medio de la autonomía, respeto y exclusividad en el Servicio de Control de la Infección Intrahospitalaria, además de mejoras en muchos aspectos de la información, de la asistencia prestada al enfermo y del secreto profesional. El predominio de actividades burocráticas y el trabajo en equipo como factor diferenciado de las actividades realizadas por el enfermero del comité, fueron aspectos relevantes aprendidos por los enfermeros asistenciales.

DESCRIPTORES: Ética, Ética en enfermería, Infección Hospitalaria/prevención y control

\section{INTRODUÇÃO}

Tanto no setor público quanto no privado, vemos trabalhadores da área da saúde frente a situações difíceis para o exercício adequado de suas profissões. Vários são os fatores determinantes políticos, sociais e econômicos, que levam às duplas e, às vezes, até triplas jornadas de trabalho, o que faz com que os profissionais não estabeleçam vínculos maiores com a instituição e mesmo com o cliente, desmotivem-se, favorecendo, dessa forma, uma desumanização da assistência prestada, além de os ganhos salariais serem inversamente proporcionais à importância das inúmeras atividades que exercem.

Em contrapartida, a clientela que procura os serviços de saúde acaba sendo alvo de desrespeito e de violação a seus direitos por parte dos profissionais que prestam assistência. "O respeito à pessoa humana é um dos valores básicos da sociedade moderna, fundamentando-se no princípio de que cada pessoa deve ser vista como um fim em si mesma e não somente como um meio, princípio freqüentemente infringido nas instituições de assistência à saúde"(1).
O ser humano, considerado um ser histórico-social, que interage com a natureza, o meio onde vive e o próprio homem, por meio das relações de produção que estabelece, necessita não somente de normas e leis que direcionem suas ações, mas também, mais do que isso, tem o direito de buscar respostas satisfatórias para as suas necessidades. Em virtude de busca de assistência à saúde, fica à mercê de instituições e profissionais, perdendo sua condição de cidadão, sendo considerado sujeito passivo, dependente e submetido a condutas paternalistas e, às vezes, até autoritárias.

Cabe mencionar que as políticas de saúde após 1964 contribuíram para uma medicina curativa, individualista e assistencial, marcada pela privatização da assistência, sendo esta extremamente especializada ${ }^{(2)}$. Políticas de compressão salarial e repressão junto à classe trabalhadora, impedindo sua organização, teve como resultado uma assistência médica elitizada e tecnológica.

Tais situações remetem-nos aos problemas éticos "ligados à alocação de recursos, portanto, de cunho político, mas com repercussões na formação e na prática dos profissionais de saúde"(2). 
Acreditamos que os profissionais que atuam diretamente na Comissão de Controle de Infecção Hospitalar - C.C.I.H., bem como aqueles que participam enquanto membros da equipe de saúde e que deveriam exercer suas atividades em conjunto, por meio da multidisciplinariedade, sentem-se, muitas vezes, devido a inúmeras situações conflitantes entre a teoria e a prática, imersos em dúvidas quanto ao que fazer e como fazer para solucionar problemas envolvendo competência, compromisso, responsabilidade, honestidade, diante do seu agir e pensar ético, levando em consideração a individualidade, potencialidades, respeito e direitos do ser humano.

A problemática enfrentada pelos profissionais de saúde, apesar de eles terem seus Códigos de Ética norteadores de suas ações, exige, muitas vezes, uma tomada de decisão que seja não somente apoiada nas normas expressas nos códigos vigentes, mas que implique atitudes que venham ao encontro das necessidades vivenciadas no cotidiano do seu trabalho. Em virtude de tantas mudanças ocorridas no enfoque da ética, nos últimos anos, os códigos já não são suficientes para o direcionamento dessas profissões. O profissional de saúde não pode restringir-se única e exclusivamente ao Código. Necessita ter conhecimento dos outros instrumentos que respaldam suas ações.

Para tanto, este estudo tem como objetivos: resgatar as percepções dos enfermeiros de C.C.I.H. sobre as questões éticas inerentes a sua prática profissional e apreender a visão dos enfermeiros assistenciais em relação à prática profissional do enfermeiro da C.C.I.H., tendo em vista os aspectos éticos.

\section{METODOLOGIA}

Trata-se de um estudo descritivo, realizado segundo a metodologia qualitativa, sendo utilizado o método da análise de conteúdo $^{(3)}$. O caminho metodológico percorrido foi viabilizado por meio do uso da técnica de entrevista.

Local do estudo

Este estudo foi desenvolvido em sete hospitais de uma cidade do Oeste do Estado do Paraná, os quais prestam atendimentos em diversas especialidades, sendo um público e os demais mistos, com atendimentos pelo Sistema Único de Saúde - S.U.S., por convênios e particulares. Uma dessas instituições hospitalares foi utilizada para validar o instrumento de coleta de dados, sendo, portanto, analisados os dados de seis instituições.

Sujeitos da pesquisa

Enfermeiros atuantes em C.C.I.H. e enfermeiros assistenciais das referidas instituições constituíram o universo desta pesquisa. O grupo de estudo correspondeu à totalidade dos enfermeiros atuantes nas C.C.I.H. dessas entidades. Quanto aos enfermeiros assistenciais, a amostra formouse com aqueles atuantes em Centro Cirúrgico, U.T.I. e Supervisão de Unidades. Essa escolha deu-se pelo fato de que, nesse contexto empírico de investigação, são esses os profissionais que mais proximamente se relacionam com os enfermeiros das C.C.I.H e com pacientes portadores de infecções hospitalares. 
Para a realização das entrevistas, elaboramos, de acordo com a Resolução 196/ 96, um Termo de Consentimento Livre e Esclarecido, que foi assinado por todos os participantes do estudo.

\section{RESULTADOS E DISCUSSÃO}

\section{Caracterização dos entrevistados}

Dos 14 sujeitos entrevistados, todos são do sexo feminino, com idades entre 22 e 45 anos, com predomínio na faixa etária de 30 a 35 anos. Observamos que 11 deles tiveram sua formação profissional em nível de graduação em Escola Pública Estadual. Em relação ao tempo de conclusão do curso de graduação, há um predomínio de profissionais enfermeiros graduados entre 4 a 7 anos, com tempo de admissão na Instituição, variando entre 0 a 9 anos, como enfermeiros.

A maioria exerce suas atividades na Comissão de Controle de Infecção Hospitalar. Em contrapartida, um dado que nos chamou atenção foi referente ao acúmulo de função por parte das entrevistadas, ou seja, 6 enfermeiras exercem outras atividades que não a específica para a qual foram contratadas.

Outro dado de extrema relevância que devemos levar em consideração está relacionado à jornada de trabalho dessas profissionais, a qual varia entre 23 e 44 horas semanais. De acordo com a Portaria № 2616/ GM do M.S. ${ }^{(4)}$, os profissionais atuantes na referida Comissão devem exercer suas atividades de acordo com a carga horária prevista. Nesse sentido, o profissional enfermeiro deverá dedicar, no mínimo, 6 horas diárias de trabalho na C.C.I.H. para cada 200 leitos, ou fração desse número, levando em consideração o número de leitos existentes. Segundo a mesma portaria, na instituição que destinar leitos a pacientes críticos, os membros devem acrescer duas horas semanais de trabalho para cada 10 leitos ou fração.

A falta de cursos de especialização ou treinamento específico na área de atuação também foi predominante. Ressaltamos a importância de o profissional enfermeiro da C.C.I.H. estar atualizando seus conhecimentos na área, em virtude das transformações tecnológicas e novas descobertas da ciência na prevenção e controle das infecções hospitalares.

Análise dos dados obtidos nas entrevistas

Os dados coletados por meio de entrevistas, que serão apresentados a seguir, estão relacionados com a área temática identificada, a saber: a prática profissional do enfermeiro da C.C.I.H., tendo como núcleos de sentido os aspectos administrativos da prática profissional do enfermeiro da C.C.I.H., os aspectos legais da prática profissional do enfermeiro da C.C.I.H. e os aspectos éticos da prática profissional do enfermeiro da C.C.I.H.

Aspectos administrativos da prática profissional do enfermeiro de C.C.I.H.

A qualidade das ações exercidas pelos enfermeiros de C.C.I.H. está diretamente relacionada, entre outros fatores que não nos cabe aqui enumerar e/ou discutir, ao tempo disponibilizado para o cumprimento das atividades na referida Comissão.

$\mathrm{Na}$ realidade analisada, a não exclusividade do trabalho do enfermeiro, tanto 
no Serviço como na Comissão de Controle de Infecção Hospitalar, está prejudicada. Muitas vezes, o enfermeiro é contratado para exercer suas atividades na Comissão, ao mesmo tempo em que ocupa outro cargo que poderia estar sendo desempenhado por outro profissional, conforme o seguinte dizer: Atualmente desenvolvo quatro horas na função de supervisão de duas Unidades de Internamento, restando apenas duas horas para atuar em C.C.I.H. (E9 EC Q1).

Acreditamos que, sendo a Portaria vigente norteadora da organização e competências de tais profissionais, ela deveria aprofundar vários aspectos relevantes da prática cotidiana do enfermeiro de C.C.I.H., principalmente tantas divergências entre a teoria e a prática.

Outro fator que favoreceria a permanência do enfermeiro com exclusividade no Serviço, ou na Comissão, seria a maior fiscalização dos órgãos competentes, exigindose, dessa forma, que as instituições de saúde se responsabilizassem pela contratação de profissionais exclusivos para tal função.

Os enfermeiros que atuam na referida Comissão, também deveriam assumir uma postura de compromisso, responsabilidade e competência com o trabalho realizado, não aceitando atribuições dúbias em uma mesma jornada de trabalho o que, conseqüentemente, acarreta uma diminuição da qualidade dos serviços prestados, atingindo diretamente a clientela assistida.

Sabemos, entretanto, que as políticas econômicas e de saúde vigentes no Brasil determinam ações inversamente proporcionais ao ideal esperado. Vemos instituições de saúde sendo fechadas por falta de verbas ou por procedimentos ilegais realizados, funcionários mal remunerados, tendo que trabalhar até dezoito horas por dia, para satisfazer suas necessidades de sobrevivência, sendo, dessa forma, humanamente impossível prestar ao paciente uma assistência digna a que ele tem direito.

Como elementos integrantes de uma equipe multiprofissional em que cada um desempenha atividades de acordo com a área de interesse e atuação, ficamos diante de algumas situações discordantes em relação à prática profissional de cada um.

As atividades desenvolvidas pelos enfermeiros que compõem a C.C.I.H. são bastante distintas, pois eles devem exercer ações técnicas, burocráticas, de educação continuada, dentre outras.

Entretanto, como muitas funções exercidas pelos enfermeiros de C.C.I.H. demandam ações burocráticas, o enfermeiro assistencial percebe a ausência do profissional enfermeiro da C.C.I.H. nas atividades ligadas à assistência de enfermagem, como mostra a fala a seguir: A meu ver, a prática do profissional enfermeiro em C.C.I.H. está centrada na burocracia, eles vão muito de encontro às papeladas que se criou em torno da C.C.I.H., é busca passiva, busca ativa, todos aqueles documentos, eles se preocupam mais com o burocrático (E11 EA Q1).

A não realização do trabalho em equipe pelo enfermeiro da Comissão e demais enfermeiros que compõem o quadro de funcionários também foi vista como fator relevante pelo enfermeiro assistencial, mencionado na seguinte fala: $E u$ acho que a enfermeira da C.C.I.H. deveria trabalhar em equipe com a enfermeira da U.T.I. no caso, para organizar treinamento, atualização de técnicas, pois, na enfermagem, há muita mudança (E14 EA Q1).

Nas Instituições hospitalares, a equipe multiprofissional atua desenvolvendo suas 
atividades dentro de um contexto em que o paciente é fragmentado, visto como um ser humano divisível em especialidades e até em ações.

Diante disso, apesar de existir uma convicção, por parte da equipe de saúde, de que o trabalho seja realizado em equipe, ele acontece de forma individualizada, fragmentada e descontextualizada da realidade em que se apresenta.

Os enfermeiros, nos idos dos anos 40, trabalhavam mais junto ao paciente, pois eram um número considerado adequado. Após a II Guerra Mundial, começaram a surgir outras classes de profissionais em enfermagem, e ao enfermeiro passou a se distanciar do cuidado direto e se ateve às práticas administrativas, porque o número de enfermeiros cada vez se tornava menor que o dos auxiliares. $E$ isso vem se repercutindo até os dias atuais.

O enfermeiro da C.C.I.H., dentro da estrutura hospitalar, desempenha funções determinadas pela Portaria em vigor, sendo que muitas atividades são de cunho burocrático, o que o distancia do cuidado mais direto com o paciente. O enfermeiro de Unidade, o qual, por sua vez, assume tarefas administrativas e assistência de maior complexidade junto ao paciente, sente a necessidade de maior envolvimento do enfermeiro da Comissão nos serviços prestados ao doente e funcionários, minimizando, dessa forma, as dificuldades encontradas para a realização de um trabalho em conjunto, objetivando os mesmos ideais.

Ressaltamos, porém, que a assistência de enfermagem está sendo prestada a uma sociedade capitalista, ou seja, vem sendo desenvolvida em instituições com objetivos divergentes, de acordo com a filosofia imposta, que nem sempre priorizam o bem-estar do usuário do Sistema de Saúde, conforme relatado por uma das entrevistadas a seguir: Dentro desse contexto redução de custos, tempo curto e acelerado de atividades acabamos caindo nessa rotina, esquecendo os direitos do paciente e os nossos deveres assumidos perante ele... (E6 EA Q1).

Aspectos legais da prática profissional do enfermeiro da C.C.I.H.

A conscientização das autoridades constituídas e dos dirigentes de Unidades de Saúde, da importância da participação do enfermeiro no processo de controle das infecções hospitalares faz-se necessária para o fornecimento de recursos físicos, humanos e materiais suficientes para o desenvolvimento de ações preventivas no combate às infecções hospitalares.

Concordamos com alguns autores ${ }^{(5)}$ quando afirmam que "uma enfermagem eficiente e com disponibilidade de recursos levará, sem dúvida, a alta precoce e a menor retorno dos pacientes aos ambulatórios, com infecção pós-operatória; devolvendo as pessoas mais cedo a suas atividades com acentuada redução dos custos hospitalares".

No entanto, somente a distribuição de recursos eqüitativos não garante a eficácia e eficiência de uma Comissão de Controle de Infecção Hospitalar. A cooperação e o interrelacionamento de todos os profissionais da área da saúde e áreas afins são fatores primordiais para o sucesso de qualquer programa $^{(6)}$.

A prática profissional do enfermeiro na C.C.I.H. é influenciada pela importância atribuída ao profissional na instituição. Cotidianamente, observamos que as instituições, mais precisamente seus 
administradores e diretores, constituem formalmente a C.C.I.H., sendo este um órgão de assessoria à autoridade máxima da instituição e de execução das ações de controle de infecção hospitalar, nomeiam os componentes por meio de ato próprio, aprovam o Regimento Interno da Comissão, mas não propiciam a infra-estrutura necessária à correta operacionalização da Comissão e não fazem respeitar o regimento interno aprovado, como descrito no seguinte dizer: Como fica a questão legal? No meu caso, o Regimento da C.C.I.H. está de acordo com a Portaria 2616, mas a prática está sufocada pelos 'Diretores' (Administradores) que insistem em não cumprir aquilo que eles não vêem como prioridade... (E9 EC Q1).

Dessa forma, os enfermeiros atuantes na Comissão são formalmente responsáveis pela C.C.I.H., porém não existe o apoio necessário da Instituição ao desenvolvimento das atribuições, faltando-lhes, muitas vezes, autonomia para a tomada de decisões, de acordo com a fala descrita a seguir: Percebi, então, que era responsável pela C.C.I.H., porém não tinha apoio nenhum... Se o profissional enfermeiro é um profissional-chave para a C.C.I.H., por que não Ihe dão a autonomia necessária? (E9 EC Q1).

Autonomia refere-se à liberdade de pensamento e de ação das pessoas, para decidirem e optarem entre as alternativas que Ihe são apresentadas, livre de coações internas e externas $^{(1)}$.

A prática profissional do enfermeiro na C.C.I.H. também é marcada por momentos distintos, dependendo de sua experiência na área. Como a maioria assume as funções inerentes à Comissão apenas com conteúdos ministrados durante a Graduação e, muitas vezes, esses conteúdos são vistos superficialmente, sentem-se despreparados diante de tantas competências e atribuições, agravados pela não valorização do trabalho realizado pelos outros membros da equipe de saúde, de acordo com a fala expressa a seguir: ...ela não tem o valor devido, o profissional de nível médio, o auxiliar de enfermagem, também não aceita com bons olhos o profissional enfermeiro do Serviço... (E7 EC Q1). Segundo alguns autores ${ }^{(7)}$, "um valor é uma convicção pessoal sobre a importância de uma dada idéia ou comportamento".Sendo o profissional de enfermagem o elo entre o paciente e demais profissionais de saúde, a prática exige que ele atue dentro das regras legais e éticas e que, ao mesmo tempo, se mantenha fiel a um sistema de valores pessoais, assegurando a qualidade da assistência, solução satisfatória entre os conflitos de valores do ponto de vista profissional e que os direitos dos pacientes sejam respeitados ${ }^{(7-10)}$.

A socialização promove a aquisição de outros valores também fundamentais para o desenvolvimento do trabalho do enfermeiro, como a competência e a confiabilidade. Mas, para que ambos ocorram, tanto os valores pessoais como os ideais para o trabalho precisam ser similares. Sendo eles incompatíveis ou dissociados, o enfermeiro, provavelmente, sentir-se-á frustrado e insatisfeito.

Aspectos éticos da prática profissional do enfermeiro da C.C.I.H.

Um dos dilemas éticos recuperados pelos enfermeiros que fazem parte da C.C.I.H., diz respeito a vários aspectos da informação.

Inserido na instituição hospitalar, o cliente é submetido a vários tipos de procedimentos, sem receber qualquer 
informação por parte da equipe que lhes presta assistência, de acordo com o seguinte depoimento: Outra coisa: 'o paciente tem direito a informações claras'. Às vezes vem aquele pessoal do sítio, que não sabe o que é uma agulha, nada, e, muitas vezes, os profissionais não se preocupam em explicar (E10 EC Q3).

Sentindo a necessidade de alertar e conscientizar os pacientes sobre seus direitos constitucionais e os instrumentos para exercêlos, em janeiro de 1995, representantes das associações de portadores de patologias, integrando o Conselho Estadual de Saúde, com apoio de outros órgãos, lançaram a Cartilha dos Direitos do Paciente ${ }^{(11)}$.

O item 8 dessa Cartilha diz que "o paciente tem direito a informações claras, simples e compreensivas, adaptadas à sua condição cultural, sobre as ações diagnósticas e terapêuticas, o que pode decorrer delas, a duração do tratamento, a localização de sua patologia, se existe necessidade de anestesia, qual o instrumento a ser utilizado e quais regiões do corpo serão afetadas pelos

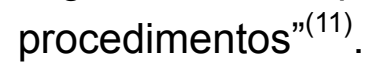

Durante o período de hospitalização, o cliente entra em um sistema de normas e rotinas pré-estabelecidas, perdendo o vínculo com a família, já que os horários de visitas são bastante restritos, priorizando determinações internas.

O paciente hospitalizado, ao ser retirado de seu ambiente familiar, encontra, no hospital, um mundo completamente estranho onde rotinas e normas rígidas controlam e determinam suas ações. Nesse contexto, sente-se amedrontado, perdido, carente de afeto. Nesse sentido, o enfermeiro pode contribuir para a humanização das normas e rotinas hospitalares ${ }^{(12)}$.
Os familiares, por sua vez, também são vitimados pela falta de informações as quais, geralmente, são transmitidas por telefone e, no horário limitado de visitas, as orientações não são repassadas de forma adequada aos membros da família, pela falta de tempo, por não ser uma rotina, e outras vezes, pelo fato de o próprio profissional não saber sobre o que pode e deve informar, conforme depoimento a seguir: Na questão dos familiares, o que nos é solicitado é repassar as normas e rotinas do hospital, mas é difícil um contato pelos horários que temos e também pela população do hospital ser numerosa, os horários de visitas são específicos de final de semana, o que se torna um pouco difícil (E5 EA Q1).

De acordo com os deveres profissionais expressos no Código de Ética dos Profissionais de Enfermagem, em seu Capítulo IV, artigo 26, o profissional de enfermagem tem o dever de "prestar adequadas informações ao cliente e família a respeito da Assistência de Enfermagem, possíveis benefícios, riscos e conseqüências que possam ocorrer"(13).

As atividades dos membros da Comissão, principalmente do enfermeiro, são desenvolvidas levando em consideração o método de vigilância epidemiológica mais adequado às características do hospital, à estrutura de pessoal e à natureza do risco de assistência, com base em critérios de magnitude, gravidade, redutibilidade das taxas ou custo, conforme a Portaria 2616/GM do M.S. ${ }^{(4)}$.

Envolvidos em tantas atividades técnicas, os profissionais de enfermagem acabam esquecendo que o cliente necessita de uma atenção mais individualizada, levando em conta suas carências pessoais, emocionais, econômicas e não apenas do cuidado dispensado a sua patologia, ao curativo e administração correta de medicamentos, de 
acordo com a fala que se segue: Ele não pode ser visto como um alvo jamais, ele tem que ser visto como uma pessoa que precisa de atendimento, precisa de assistência e, principalmente, de profissionais que tenham atenção, carinho e não apenas um remédio numa bandeja, de hora em hora, e que não só entrem no seu quarto para fazer um curativo quando já não dá mais para suportar o curativo molhado ou apenas para trocar os lençóis quando o paciente não tem controle de suas necessidades fisiológicas: que sejam pessoas humanas acima de qualquer outro fator, que olhem naquele indivíduo o colega, um irmão de sangue, um indivíduo que precisa de alguém (E7 EC Q4).

Na Cartilha dos Direitos do Paciente, o item 1 traz que "o paciente tem direito a atendimento humano, atencioso e respeitoso por parte de todos os profissionais de saúde"(11).

Em se tratando de prevenção e controle das infecções hospitalares, uma questão um tanto quanto polêmica e que envolve aspectos éticos merecedores de serem analisados, diz respeito ao sigilo profissional versus direito do paciente em receber informações acerca do seu estado de saúde, diagnóstico e prognóstico. Como, por exemplo, o profissional deve revelar ao paciente que este adquiriu uma infecção hospitalar, considerando os fatores inerentes ao próprio paciente, aos procedimentos diagnósticos e terapêuticos, ao ambiente hospitalar $e$ aos outros fatores que desencadeiam a causalidade das infecções hospitalares e que nem sempre são por nós profissionais controlados? Ou ainda, o paciente tem o direito de saber que, durante o período de hospitalização, foi vítima de uma infecção nosocomial?

Entre os enfermeiros de C.C.I.H. entrevistados, notamos uma certa divergência entre as respostas obtidas, como vemos a seguir: Mesma coisa as infecções hospitalares, você faz a busca, você detecta, você monitora, você orienta o funcionário, mas ele tem que agir com ética também, sem sair, por exemplo, discutindo na esquina, acho que isso tem que ser preservado dentro da Instituição (E13 EC Q2). ...se você, dentro do controle de infecção hospitalar, detecta que o paciente tem infecção hospitalar, é de direito do paciente estar sabendo(E13 EC Q4). A partir do momento que tem diagnosticado, que o médico passa, fica bem claro para o paciente (E13 EC Q4).

Os enfermeiros de C.C.I.H., por desenvolverem ações na busca ativa das infecções hospitalares, colocam-se frente a situações embaraçosas. Ao se apresentar como membro da Comissão, questionar o paciente sobre hipertermia, aspecto do curativo, dores, e, ao realizar o exame físico para certificar-se das informações colhidas, a dúvida surge para o paciente e ele pergunta: Estou com infecção hospitalar?

Se o intuito da busca ativa é prevenir o aparecimento de infecção hospitalar, torna-se fácil explicar ao paciente os motivos dos questionamentos e das técnicas realizadas. Mas, se o objetivo é amenizar os efeitos da infecção instalada, qual deve ser a postura do profissional? Calar-se, negando a si mesmo os direitos do paciente em receber informações sobre o seu estado atual ou explicar-lhe sobre o ocorrido, fazendo com que ele participe das intervenções necessárias para o total restabelecimento das funções do paciente?

Acreditamos que calar-se diante de tal fato faz com que o profissional atenda aos interesses da instituição, ao mesmo tempo em que infringe os postulados éticos do Código de Ética, norteador de sua profissão e dos direitos do paciente.

Frisamos que o diagnóstico definitivo de casos suspeitos de infecção nosocomial está na dependência de exames laboratoriais mais complexos, além do parecer do médico assistente ou do médico da própria Comissão. 
Entretanto, ao receber o diagnóstico confirmativo de infecção hospitalar, o médico também, na grande maioria das vezes, não repassa tal informação ao paciente, buscando alternativas paliativas para justificar a permanência do paciente além do esperado no hospital, o retorno ao centro cirúrgico para drenar secreções internas, entre outras.

$O$ fato de explicar ao paciente sobre o quadro infeccioso também não é uma tarefa fácil, diante de tantas inverdades acerca do assunto infecção hospitalar. Acreditamos que o paciente informado e instruído sobre o que é, como se manifesta, quais são as probabilidades de se adquirir uma infecção nosocomial, passa a participar de seu tratamento, entendendo que a infecção hospitalar não ocorre exclusivamente por culpa do hospital, mas por uma série de fatores já comentados anteriormente, exigindo, também, uma maior qualidade na assistência prestada por parte da equipe multiprofissional.

Contudo, acreditamos que as questões éticas envolvidas na prática profissional de enfermeiros que compõem a Comissão de Controle de Infecção Hospitalar devem ser discutidas e aprofundadas de acordo com as necessidades vivenciadas no âmbito de cada Instituição hospitalar.

\section{CONSIDERAÇÕES FINAIS}

A importância atribuída ao trabalho exercido pela C.C.I.H. dentro das instituições hospitalares ainda não foi totalmente percebida por parte dos diretores, administradores e equipe multidisciplinar. Acreditamos que somente uma mudança em nível local não seja suficiente para o alcance do reconhecimento desejado e almejado por esses profissionais.
Haveria

necessidade

de transformações de cunho governamental, como investimentos na área de treinamentos e pósgraduação, ou seja, com a formação de recursos humanos suficientemente capacitados para o acompanhamento das instituições de saúde para o correto exercício desses profissionais. Em nível local, ou seja, dentro das instituições de saúde, o reconhecimento profissional garantido pela plena autonomia, respeito aos membros da comissão, além de jornadas de trabalho que não ultrapassem as 6 horas diárias para cada duzentos leitos, mantendo-se a exclusividade no serviço, seriam algumas das maneiras de contribuição para um melhor desempenho dos referidos profissionais, beneficiando, dessa forma, não somente a instituição, mas também os pacientes, a família e a comunidade.

As escolas, enquanto centros formadores de recursos humanos, deveriam manter, em seus currículos, disciplinas direcionadas para o assunto "infecção hospitalar", contribuindo para que o futuro profissional insira-se na realidade que a ele se apresenta.

Os profissionais, por sua vez, precisam buscar novos conhecimentos, habilidades e atitudes na área, fazendo com que, cada vez mais, seu trabalho seja valorizado e, ao mesmo tempo, indispensável dentro das instituições prestadoras de assistência à saúde.

Este estudo, portanto, deve ser considerado uma aproximação ao tema proposto, e seu objetivo é constituir-se em contribuição, mesmo que pequena, para a maior compreensão das questões éticas envolvidas na prática profissional de enfermeiros da Comissão de Controle de Infecção Hospitalar. 


\section{REFERÊNCIAS BIBLIOGRÁFICAS}

1. Fortes PAC. Ética e saúde: questões éticas, deontológicas e legais, tomada de decisões, autonomia e direitos do paciente, estudo de casos. São Paulo (SP): EPU; 1998.

2. Germano RM. A ética e o ensino da ética na Enfermagem do Brasil. São Paulo (SP): Cortez; 1993.

3. Bardin L. Análise de conteúdo. Lisboa (Portugal): Edições 70; 1977.

4. Ministério da Saúde (BR). Portaria $n^{\circ} 2.616$ de 12 de maio de 1998. Dispõe sobre diretrizes e normas para a prevenção e o controle das infecções hospitalares. Diário Oficial da República Federativa da União. Brasília (DF): Ministério da Saúde; 1998.

5. Almeida LMQ, Cavalcante RG. Atribuições do serviço de enfermagem na prevenção e controle da infecção hospitalar. Rev Paul Enfermagem 1985 outubro/ dezembro; 5(4):149-51.

6. Mendes HWB, Caldas AL Júnior. Prática profissional e ética no contexto das políticas de saúde. Rev Latinoam Enfermagem 2001 maio; 9(3):20-6.

7. Potter P, Perry A. Grande tratado de Enfermagem prática: clínica e prática hospitalar. São Paulo (SP): Santos; 1996.

8. Mendes IAC. O talento humano ao encontro da qualidade e da ética do cuidado. Rev Latino-am Enfermagem 2000 dezembro; 8(6):1.

9. Mendes IAC. Investimentos éticos no limiar da nova era. Rev Latino-am Enfermagem 1999 outubro; 7(4):1.

10. Trevizan MA, Mendes IAC, Lourenço MR, Shinyashiki GT. Aspectos éticos na ação gerencial do enfermeiro. Rev Latino-am Enfermagem 2002 janeirofevereiro;10(1):85-9.

11. Guedes JS. Direitos do paciente. In: Pessini L, Barchifontaine CP. Problemas atuais de bioética. $4^{\mathrm{a}} \mathrm{ed}$. São Paulo (SP): Loyola; 1997. p. 455-60.

12. Tesck ECB. Um aspecto da responsabilidade da enfermeira na assistência integral ao paciente hospitalizado - a participação de familiares. Enf Novas Dimensões 1976; 1(6):351-3.

13. Santos EF, Santos EB, Assis MF, Santana GO, Meneses RO. Legislação em Enfermagem: atos normativos do exercício e do ensino de enfermagem. São Paulo (SP): Atheneu; 1997. 